\title{
Effects and consideration of storm movement in rainfall-runoff modelling at the basin scale
}

\author{
Shahram Khalighi Sigaroodi ${ }^{1,2}$ and Qiuwen Chen $^{2,3}$ \\ ${ }^{1}$ Faculty of Natural Resources, University of Tehran, Tehran, Iran \\ ${ }^{2}$ RCEES Chinese Academy of Sciences, Beijing, 100085, China \\ ${ }^{3}$ CEER Nanjing Hydraulics Research Institute, Nanjing, 210023, China \\ Correspondence to: Qiuwen Chen (qwchen@ nhri.cn)
}

Received: 21 July 2016 - Published in Hydrol. Earth Syst. Sci. Discuss.: 7 September 2016

Revised: 25 November 2016 - Accepted: 29 November 2016 - Published: 21 December 2016

\begin{abstract}
A number of studies have emphasized the effects of rainfall movement on runoff simulation; nevertheless, due to the lack of rain gauges inside sub-basins, a method using a hyetograph of the nearest gauges to a sub-basin is usually employed. This study investigated the effects of neglecting rainfall movement on overland simulation results in even a middle-sized basin. Simulations were carried out under two conditions: (1) stationary conditions where the nearest gauge hyetograph was used and rainfall movement was ignored, which is quite common in the case of a lack of data, and (2) moving conditions where a shifted hyetograph based on hyetograph timing recorded in the basin was used. The simulation results were compared with the measured discharge at the outlets. The results revealed that using the shifted hyetograph, which could consider the rainfall movement over subbasins, decreased the mismatches between the simulated and observed hydrograph. In some of the cases, the shifted hyetograph reduced the relative difference more than $20 \%$. The study provided a useful method to cope with rainfall movement in runoff modelling of sparsely gauged large watersheds.
\end{abstract}

\section{Introduction}

Since the first reports in the 1960s (Maksimov, 1964; Yen and Chow, 1968; Lee et al., 2015) emphasized that higher peak flows are generated whenever the precipitation moves from upstream toward downstream; conversely, rainfall passing from down- to upstream results in a rounded hydrograph, a great deal of research has investigated the effects of rain- fall movement on the shape of the runoff hydrograph in the past half century. Most studies (Ngirane and Weather, 1985; Singh, 1997, 1998) have applied mathematical approaches to obtain a better understanding of the effects of storm speed and direction characteristics on the hydrograph shape. Their results showed that hyetograph characteristics, such as rainfall pattern, duration, intensity, direction and speed, significantly affected the hydrograph shape, and they emphasized that downward storm movement causes an increase of the peak flow. Some researchers (Singh, 1998; Mizumura and Ito, 2011) adopted a kinematic wave equation to model the hydrograph in the case of a moving rainstorm. Their results showed that the maximum flow depth was generated when the rainstorm speed equalled the flood movement toward the outlet, and the speed of the storm had a greater impact for larger Manning's roughness coefficients. Recent studies have preferred dynamic wave models based on SaintVenant equations to obtain flexible results under varying conditions (Costabile et al., 2012). Kim and Seo (2013) applied a dynamic wave model based on shallow-water equations to study the effects of storm movement on runoff generation in a V-shaped watershed experimentation system. The results revealed that storm movement could generate a loop in the stage-discharge curve, and changes in storm movement direction could invert the rotation of the loop. In addition, they revealed that the characteristics of rating curve depended on basin characteristic rather than functions of storm movement in a V-shaped basin. In addition, there has been some research (de Lima and Singh, 2002) using rainfall simulators at laboratory scale to investigate the effects of storm movement. Laboratory portable rainfall simulators 


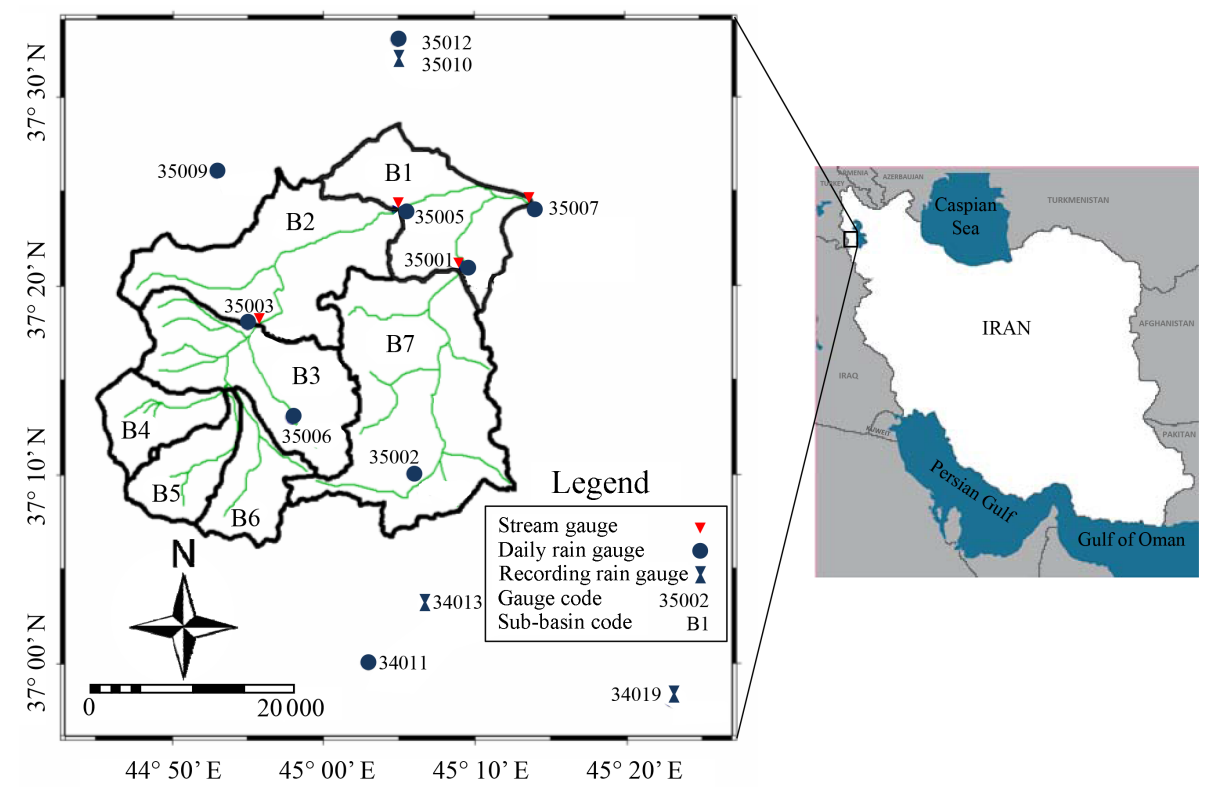

Figure 1. Barandoozchay basin and hydrometeorological gauges.

and flumes were used to simulate the hydrograph response to moving storms and subsequently soil erosion (de Lima et al., 2003). They applied different hyetograph patterns to study the effects of rainfall characteristics on the runoff hydrograph. The simulation outputs of hypothetical storms moving upward and downward over a laboratory impervious plane revealed that the peak discharges and hydrograph shape were highly affected by storm movement. In particular, they highlighted that runoff under moving rainfall is a non-linear process, essentially different from stationary rainfall. Saghafian et al. (1995) used a two-dimensional runoff model and a Monte Carlo method to investigate storm movement effects on runoff. The results indicated that when storm movement is slow, a stationary rainstorm could be used in simulations. However, when storm movement is fast, a stationary rainstorm was not acceptable. Ogden et al. (1995) showed that the runoff hydrograph was more sensitive to storm speed than direction in two-dimensional basin topography. Based on Manning's equation, the peak maximum occurred when the storm moved toward downstream at a critical speed equalling half the flow velocity.

Although there is a well-known background on the effects of moving storms on overland flow generation, most of the interest has focused on laboratory experiments (Singh, 1997, 1998; de Lima et al., 2003; de Lima and Singh, 2002) or mathematical approaches (Costabile et al., 2012; Kim and Seo, 2013; Saghafian et al., 1995; Ogden et al., 1995). These studies emphasized the effects of movement on runoff generation via a synthetic hyetograph whose direction, speed and intensity were well-controlled by the researchers. However, few studies are available about rainstorm movement effects on runoff in natural environments of real basins, especially in the case of data deficiency. Therefore, it is essential to develop an approach that supports hydrologists bridging the gap between mathematical models and real conditions. The objective of this study was (1) to precisely examine the effects of moving storms on hydrograph simulation at the basin scale using real recorded rainfall-runoff and (2) to provide an approach to consider storm movement under the conditions of data shortage in sparsely gauged basins.

\section{Materials and methods}

\subsection{Study area and data availability}

Barandoozchay basin, one of the Lake Urmia subcatchments, is located in the northwest of Iran. The study area lies in between Lake Urmia and the Iran-Iraq-Turkey international border from $44^{\circ} 45^{\prime}$ to $45^{\circ} 14^{\prime} \mathrm{E}$ and $37^{\circ} 06^{\prime}$ to $37^{\circ} 29^{\prime} \mathrm{N}$. The area of the basin is about $1146 \mathrm{~km}^{2}$.

The basin is divided into seven sub-basins (B1 to B7), based on the river branches and topographic futures. Figure 1 shows the Barandoozchay map and hydrometeorological gauges. This mountainous basin is mostly covered by grasslands, followed by farmland and orchard land. The humid air often (not always) comes from the west, originating from the Mediterranean Sea.

There are six daily rain gauges and four stream gauges inside the basin (Fig. 1), and three hourly rain gauges (35010, 34013 and 34019) around the basin.

Seven storm events, which were recorded in all rain gauges from 1995 to 2014, were selected. These events have recorded rain data (daily and hourly) available from the 

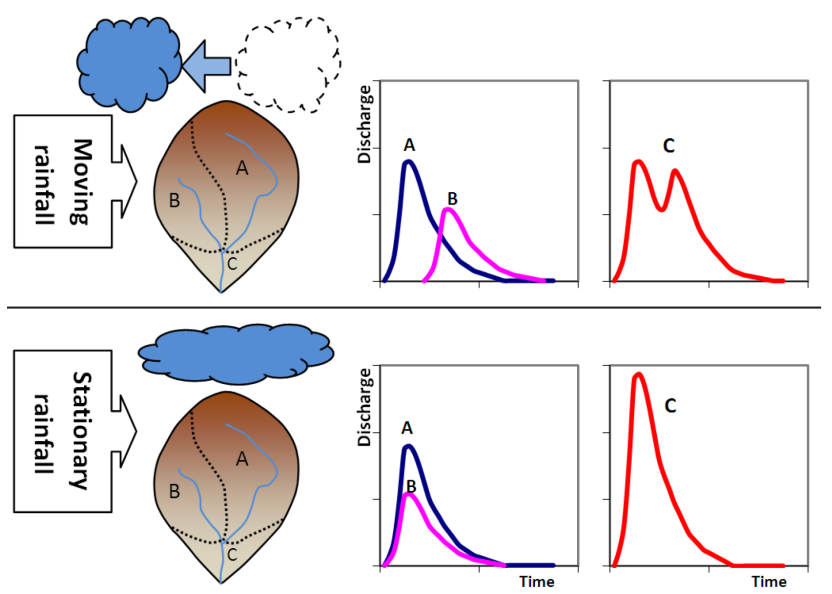

Figure 2. Schematic of rainfall movement effect on runoff formation.

nearby rain gauges and the hydrometric runoff data from the stream gauges.

\subsection{Estimation of sub-basin hyetograph}

When the cloud is stationary, most of sub-basins that are covered by the cloud react to the rainfall simultaneously, implying that the start time and end time of the rainfall event are approximately the same for all sub-basins. However, in the case of a moving cloud, the sub-basins that are located in the wind direction start to generate runoff earlier than the others (Fig. 2).

Since there is no record from the rain gauge inside the basin, the start and end time of the events were unknown. Therefore, the residence time of the storm cloud over each sub-basin and its role in outlet runoff generation were estimated and examined.

As the first step, the total daily rainfall of each sub-basin was estimated using Kriging and inverse-distance-weighting methods, based on the rain gauges inside the basin. Figure 3 shows the raster map of generated rainfall for the event on 12 May 2010.

The total daily rainfall was then disaggregated into hourly rainfall. Since there is no hourly recording gauge inside the basin, the nearest recording gauges at Urmia, Oshnavieh and Naghadeh (35010, 34013 and 34019) were used. The hourly rainfall for sub-basins was obtained through the following steps:

- First, we determine the best hyetograph from one of the stations for disaggregation. The best hyetograph was selected based on daily rainfall amounts in stations and sub-basins.

- Second, we calculate the ratio of total rainfall in a subbasin to the total daily rainfall recorded in the selected station with the best hyetograph.

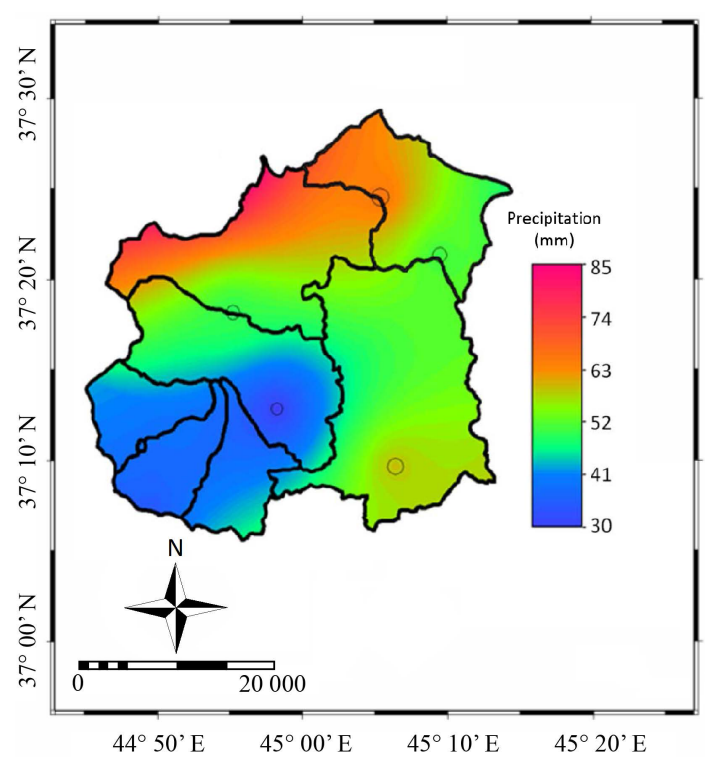

Figure 3. Spatial distribution of rainfall event on 12 May 2010.

- Third, we multiply the calculated ratio to the best hyetograph to obtain hourly rainfall of a sub-basin (Choi et al., 2008; Gyasi-Agyei, 2005; Gyasi-Agyei and Parvez Bin Mahbub, 2007). Figure 4 illustrates the procedures to disaggregate the daily rainfall into each sub-basin's hyetograph.

Due to dynamic motion of the cloud, the rainfall duration, start and end time, and intensity, as well as other characteristics, change. These parameters are known for the gauge locations but unknown in other locations as well as in subbasins. To determine the cloud arrival time of each sub-basin and the time of rainfall occurrence (start, end and duration), the recorded hyetograph was concentrated on a unique time named the time of gravity centre of hyetograph (TGCH) (Khalighi et al., 2009). Since the TGCH is specified in gauge locations, it can be calculated for sub-basins through the following procedures:

1. TGCH for recorded rainfall was calculated as a momentum of the rainfall component around the horizontal and vertical axis. Figure 5 shows that the recorded event at station 35010 started at 04:00 LT and ended at 14:30 LT, and the calculated TGCH was at 09:00 LT (8.981).

2. When a cloud moves over a basin, the rainfall time at a point depends on the point location and cloud speed and direction. At least three gauges are necessary to determine the occurrence time of rainfall at a point, although more gauges could increase the accuracy. As there are only three recording gauges around the study basin, a flat plane passes through the stations (Fig. 6). Therefore, the equation of the plane $(\mathrm{TGCH}=a X+b Y+c)$ was applied to calculate the TGCH at each point. The UTM 


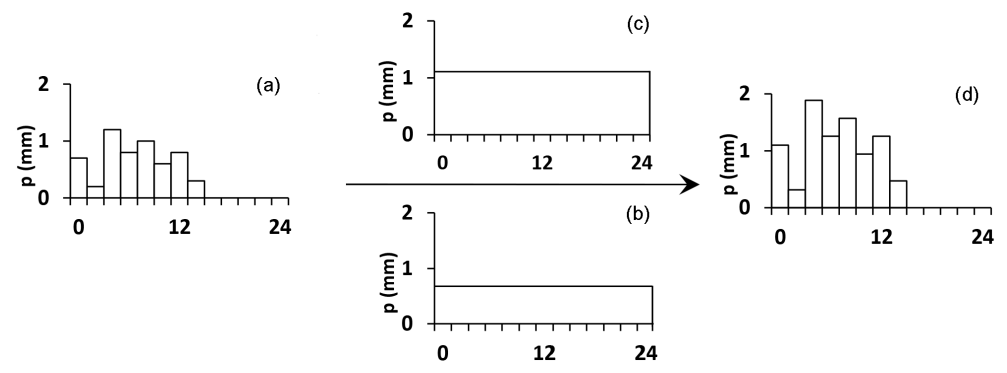

Figure 4. Schematic of rainfall hyetograph determination in sub-basin centroid. (a) Hourly hyetograph at nearest gauge, (b) daily precipitation at nearest gauge, (c) daily precipitation in sub-basin centroid, (d) derived hyetograph for sub-basin.

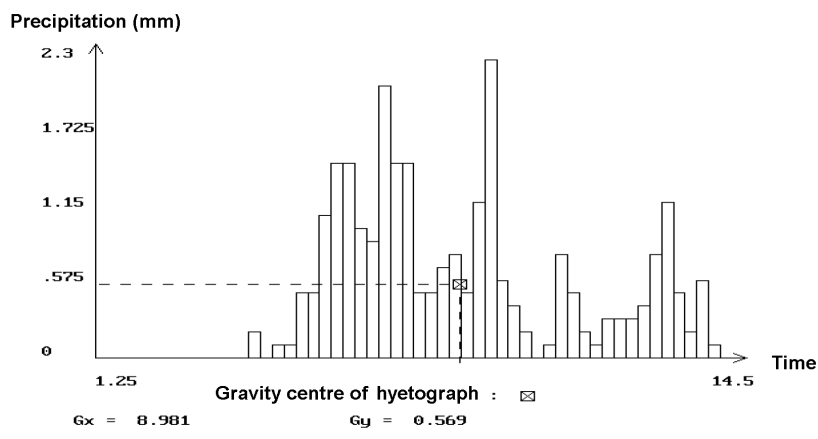

Figure 5. Calculation of hyetograph centroid (TGCH) on 22 April 1995 at station 35015 (Gx: temporal coordinates of concentrated event, Gy: average of incremental rainfall).

coordinates of the stations $(X, Y)$ are considered as independent variables, and the TGCHs are considered as a dependent variable, and then the coefficients $(a, b$ and $c)$ of the flat plane are calculated using algebraic functions (Howard, 2010).

3. The coordinates of the sub-basin centroids were placed in the above equations to determine the TGCH of each sub-basin.

4. The previously derived hyetograph was shifted as its gravity centre conformed to the TGCH of each subbasin centroid (Fig. 7).

For example, the TGCH for the event on 22 April 1995 was recorded at $8.98,6.48$ and 5.33 at the stations 35010, 34019 and 34013 respectively (Table 2). Then the equation of the TGCH plane of this event is $\mathrm{TGCH}=0.000077 \times X+0.000069+Y-317.457$. Based on this equation and the coordinates of the B1 sub-basin centroid, the TGCH was 08:00 LT, implying that the TGCH at B1 occurred almost $1 \mathrm{~h}$ earlier than at station 35010, which was 08:59 LT.

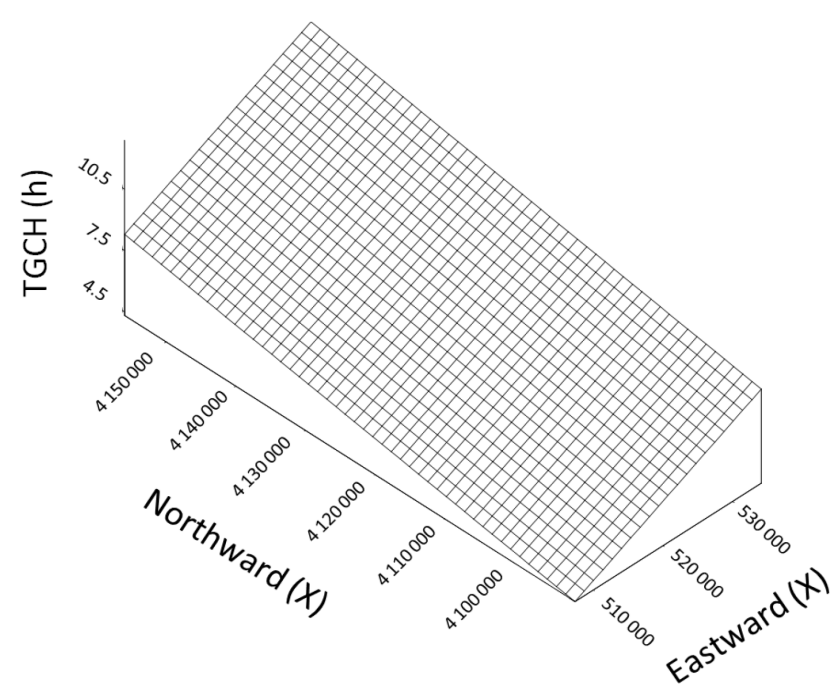

Figure 6. Flat plane passing through the TGCH for the event on 22 April 1995.

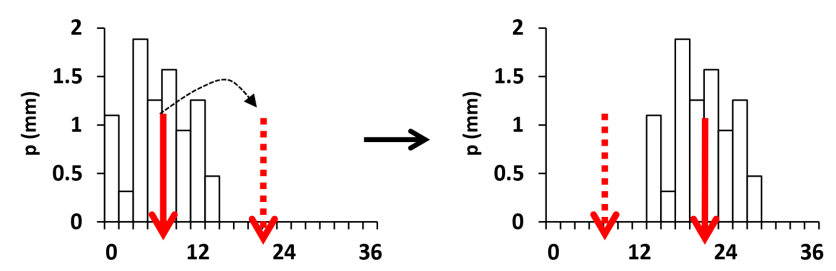

Figure 7. Shifting the hyetograph to the estimated TGCH.

\subsection{Rainfall-runoff modelling}

The HEC-HMS model (United States Department of Agriculture, 1986) was used to investigate the effects of storm movement on hydrograph simulations. The model was calibrated using five events (22 April 1995, 21 April 2002, 3 April 2003, 18 April 2006 and 7 April 2008). Based on sensitivity analysis, the relative initial abstraction $\left(R_{\mathrm{a}}=I_{\mathrm{a}} / S\right)$ is the most sensitive parameter among the other parameters such as curve number $(\mathrm{CN})$, lag time $\left(T_{1}\right)$, total storage $(S)$ and initial abstraction $\left(I_{\mathrm{a}}\right)$. Table 1 showed the primary and 
Table 1. Optimized parameter in sub-basins.

\begin{tabular}{lcrrr}
\hline Sub-basin & \multicolumn{2}{c}{$R_{\mathrm{a}}=I_{\mathrm{a}} / S$} & $\mathrm{CN}$ & $T_{l}$ \\
\cline { 2 - 3 } & Primary & Optimized & & (h) \\
\hline B1 & 0.2 & 0.197 & 68 & 7.6 \\
B2 & 0.2 & 0.18 & 71 & 6.2 \\
B3 & 0.2 & 0.23 & 78 & 3.7 \\
B4 & 0.2 & 0.23 & 80 & 2.3 \\
B5 & 0.2 & 0.23 & 78 & 3.1 \\
B6 & 0.2 & 0.23 & 82 & 2.7 \\
B7 & 0.2 & 0.164 & 77 & 5.9 \\
\hline
\end{tabular}

optimized parameters in sub-basins. The validation was conducted using the events on 12 May 2010 and 22 April 2014. The results of peak discharges are shown in Table 2.

After the calibration and validation, the simulations were carried out for all events using two hypotheses: (1) stationary cloud where the sub-basin hyetograph timing is equal to the nearest recording gauge and (2) moving cloud where the subbasin rainfall hyetograph shifted based on cloud movement direction and sub-basin location.

A Taylor diagram (Taylor, 2001, 2005; Sigaroodi et al., 2014) and root mean square of relative difference (RD) were used to compare the results of two hypothesized conditions:

$\mathrm{RD}=\sqrt{\left(\frac{P_{\mathrm{O}}-P_{\mathrm{S}}}{P_{\mathrm{O}}}\right)^{2}}+100$,

where the $\mathrm{P}_{\mathrm{O}}$ and $\mathrm{P}_{\mathrm{S}}$ are observed and simulated peak discharge respectively.

\section{Results}

Figure 8 shows the planes of TGCH for different events. Although the basin is mainly affected by the eastern humid Mediterranean air, the results indicated that each selected rainfall event had different directions and speeds.

Based on the gauge locations and TGCH of each event, a plane equation TGCH $=a X+b X+c$ was obtained for each event. Table 3 shows the equation coefficients.

The gravity centre coordinate of each sub-basin is used in the equations to calculate the TGCH for the sub-basin centroid of each event. Figure 9 shows how the sub-basin hyetograph is shifted to obtain the TGCH for the event on 3 April 2003. The measured TGCH at the gauges and the calculated TGCH for sub-basins are shown in Table 4.

Figure 10 presents the HEC-HMS modelled results for the event on 22 April 2014 at gauge 35005. The right part shows the model performance under stationary conditions where all sub-basins react to the hyetograph simultaneously. The grey and brown lines are the modelled outputs for upper subbasins, which make the simulated total output (blue line). The hydrograph is sharp and the time to peak is quite differ-
Table 2. Comparison of observed and simulated peak discharge in validation step.

\begin{tabular}{lccccc}
\hline \multirow{2}{*}{$\begin{array}{l}\text { Hydrological } \\
\text { station }\end{array}$} & \multicolumn{2}{c}{ 12 May 2010 } & & \multicolumn{2}{c}{ 22 April 2014 } \\
\cline { 2 - 3 } \cline { 5 - 6 } & Observed & Simulated & & Observed & Simulated \\
\hline 35003 & 12.2 & 14.4 & & - & - \\
35005 & 34.8 & 31.5 & & 297.9 & 352 \\
\hline
\end{tabular}

ent compared to the observed hydrograph (red line). The left part presents the modelled result using a shifted hyetograph, which matches better with the observed hydrograph.

For comparison, the modelled peak discharges of the seven selected events under the two conditions are presented together with the observations in Table 5.

Figure 11 displays the standard deviation (SD) and correlation coefficient $R^{2}$ of the modelled results under stationary and moving conditions on the Taylor diagram. It is clearly seen that the moving-condition results are closer to the observation points than the stationary-condition results.

\section{Discussion}

To achieve accurate hydrological modelling, high-quality and spatially explicit rainfall data should be accessible; however, in many cases uniform hyetographs are used for all subbasins due to lack of sufficient gauges. If the cloud motion is neglected, it means that the differences between the times of runoff generated by sub-basins are ignored. In this case, to compensate for the difference and achieve better matching between simulated and observed runoff, other basin factors such as curve number $(\mathrm{CN})$ or time lag have to be modified, which most probably cause artifacts in the coefficients (Khalighi et al., 2006, 2009).

Some researchers used portable rainfall simulators or flumes in laboratory scales (Yen and Chow, 1968; Singh, 1997, de Lima and Singh, 2002; de Lima et al., 2003), while others preferred mathematical models to detect the effects of rainfall movement on runoff generation (Saghafian et al., 1995; Ogden et al., 1995; Kim and Seo, 2013). Synthetic or artificial rainfall is used in the laboratory or mathematical simulations. In contrast to previous studies, this research investigated the effects in a real basin under natural conditions, where the rainfall characteristics cannot be controlled. If there are sufficient rain gauges in basin - at least one gauge in the middle of each sub-basin - accurate runoff simulations can be achieved. However, this is not true in most cases where sparse gauges or no gauge is available. This study provided an approach that the rainfall time in ungauged sub-basins could be determined using the recorded rainfall around gauges. Although more rain gauges can obtain better results, at least three gauges are necessary to record the rainfall event for determining the cloud direction and speed, which is reflected in the TGCH plane. 

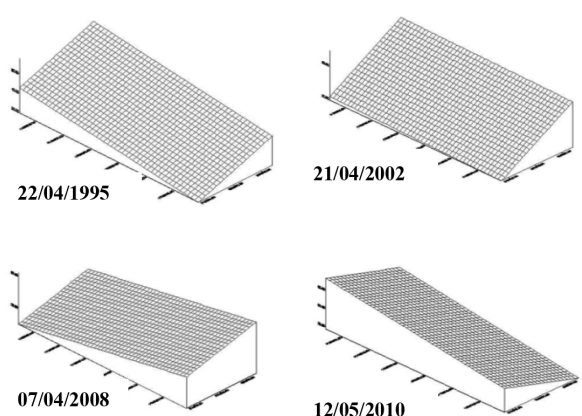
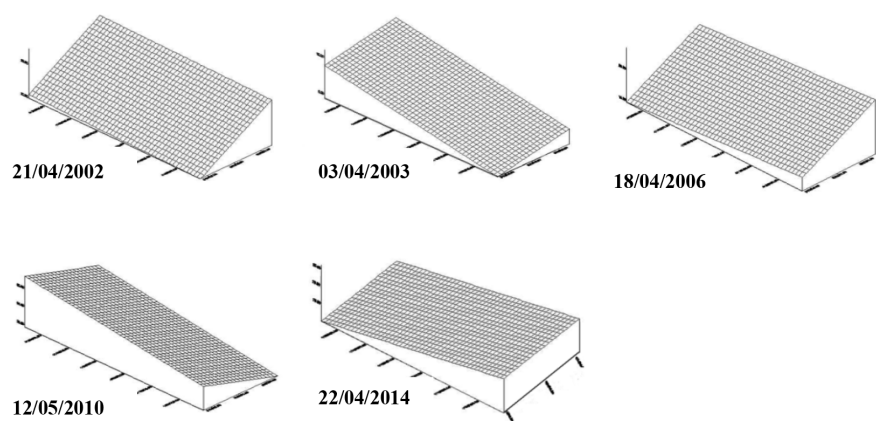

Figure 8. Precipitation time occurrence plane in different events.
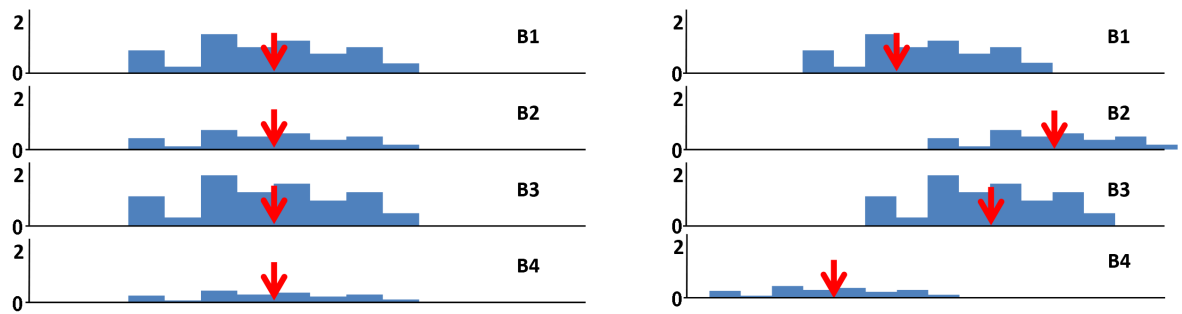

Figure 9. Hyetograph of sub-basins before shift (left panel) and after shift (right panel). (Red arrows show the timing position of TGCH before and after shifting.)

Moving simulation

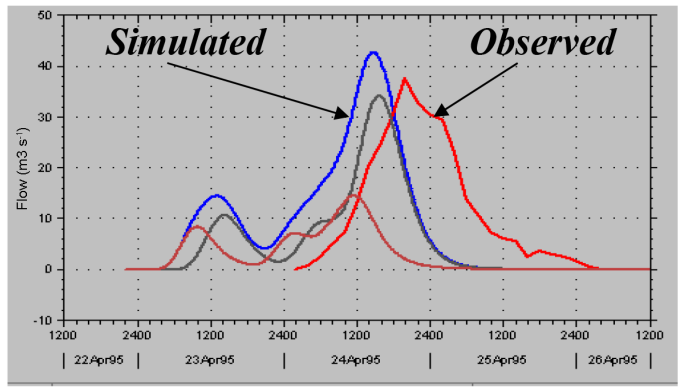

Stationary simulation

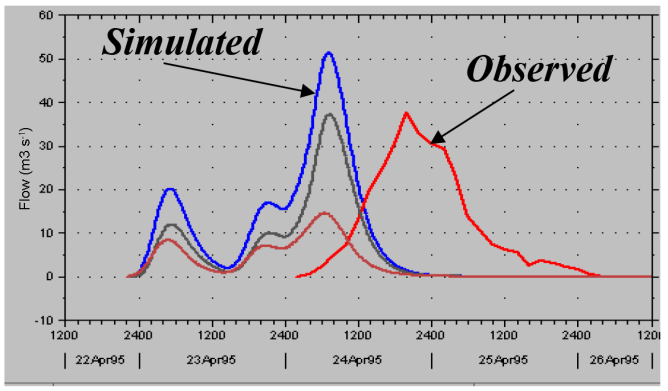

Figure 10. HEC-HMS output for rainfall event on 22 April 1995, under two different conditions: moving simulation (left panel) and stationary simulation (right panel).

When the cloud movement is slow, consideration of movement is more important than during fast movement conditions. During the event of 22 April 2014, the time difference between gauges 35010 and 34019 (Table 4) shows that the cloud movement is very low. Thus the sub-basin B1 generates runoff much earlier than B7. This result was not consistent with the findings of Saghafian (1995), who stated that a stationary rainstorm could be used in low-speed storms. This study showed that, for small basins or laboratory scales, where the cloud covers the whole basin, the storm motion effect could be ignored. However, in the case of middle-size to large basins, the runoff of low-speed storms passing over the basin has an obvious role in determining hydrograph shape. It can then be concluded that when the time difference between the recorded rainfall around the area is small, the dif- ferences between stationary and moving runoff simulations are slight. These results were consistent with the findings of previous studies, which showed the impacts of cloud motion on hydrographs by using rainfall simulators at different laboratory scales (Sing, 1997, 1998; de Lima and Singh, 2002; de Lima et al., 2003; Marzen et al., 2015) or the kinematic wave method (Mizumura and Ito, 2011).

The results of this study also revealed that longer rainfall is less affected by cloud movement. In other words, for rapid and short rainfall, the runoff hydrograph is more strongly affected by cloud movement speed and direction. These results were consistent with the findings of previous studies (de Lima and Singh, 2002; Khalighi et al., 2009; Kim and Seo, 2013) in the laboratory, which emphasized the effects of rainfall duration on runoff generations. 
Table 3. Obtained coefficients for the TGCH flat plane.

\begin{tabular}{lrrrrrrr}
\hline $\begin{array}{l}\text { Coefficient/ } \\
\text { time }\end{array}$ & 22 Apr 1995 & 21 Apr 2002 & 3 Apr 2003 & 18 Apr 2006 & 7 Apr 2008 & 12 May 2010 & 22 Apr 2014 \\
\hline$a$ & 0.000077 & 0.000256 & 0.000222 & 0.000244 & 0.000047 & $-7.3 \times 10^{-5}$ & $-8.9 \times 10^{-5}$ \\
$b$ & 0.000069 & 0.000008 & 0.000095 & $-3.4 \times 10^{-5}$ & -0.00003 & 0.000074 & -0.00019 \\
$c$ & -317.457 & -144.736 & -485.298 & 30.743 & 127.119 & -236.65 & 855.542 \\
\hline
\end{tabular}

Table 4. TGCH measured at the gauges and calculated for the sub-basins.

\begin{tabular}{|c|c|c|c|c|c|c|c|c|c|c|}
\hline \multicolumn{2}{|c|}{ Location } & \multicolumn{2}{|c|}{ UTM } & \multicolumn{7}{|c|}{ Precipitation events } \\
\hline & & $X$ & $Y$ & 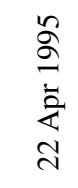 & 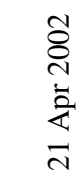 & 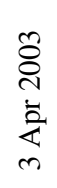 & 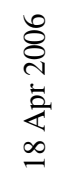 & 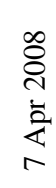 & 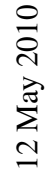 & 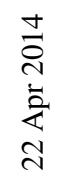 \\
\hline \multirow{3}{*}{ 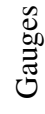 } & 35010 & 507361 & 4155960 & 8.98 & 20.4 & 7.3 & 14.7 & 3.0 & 8.3 & 15.9 \\
\hline & 34019 & 534124 & 4091310 & 6.48 & $26.7^{\mathrm{a}}$ & 6.2 & 23.4 & 6.2 & 1.6 & 25.5 \\
\hline & 34013 & 510374 & 4100492 & 5.33 & 20.7 & 1.1 & 17.3 & 4.8 & 4.0 & 25.9 \\
\hline \multirow{7}{*}{ 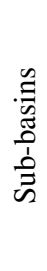 } & B1 & $510820^{\mathrm{b}}$ & 4139365 & 8.0 & 21.1 & 6.3 & 16.1 & 3.7 & 6.8 & 18.7 \\
\hline & B2 & 495670 & 4134355 & 6.5 & 17.2 & 4.5 & 12.6 & 3.1 & 7.6 & 20.9 \\
\hline & B3 & 493644 & 4123015 & 5.6 & 16.6 & 3.7 & 12.5 & 3.3 & 6.9 & 23.2 \\
\hline & B4 & 483585 & 4118992 & 4.5 & 14 & 2.8 & 10.1 & 3 & 7.3 & 24.9 \\
\hline & B5 & 486806 & 4113932 & 4.4 & 14.8 & 2.9 & 11.1 & 3.3 & 6.7 & 25.5 \\
\hline & B6 & 493217 & 4112538 & 4.8 & 16.4 & 3.2 & 12.7 & 3.6 & 6.1 & 25.2 \\
\hline & B7 & 508969 & 4120830 & 6.6 & 20.5 & 5.1 & 16.3 & 4.1 & 5.6 & 22.3 \\
\hline
\end{tabular}

${ }^{a}$ Numbers over 24 refer to the next day. ${ }^{b}$ Coordinate of centroid of sub-basin.

Table 5. Modelled peak discharges under two conditions and differences. The bold numbers show the better results.

\begin{tabular}{lcrrrrrr}
\hline & & \multicolumn{3}{c}{ Peak discharge } & & \multicolumn{2}{c}{ Difference (\%) } \\
\cline { 3 - 4 } \cline { 6 - 7 } Date & $\begin{array}{c}\text { Hydrological } \\
\text { station }\end{array}$ & Obs. & Stationary & Moving & & Stationary & Moving \\
& & & & & & \\
\hline 22 Apr 2014 & 35005 & 297.9 & 352 & 315.3 & & 18.2 & $\mathbf{5 . 8}$ \\
12 May 2010 & & 34.8 & 31.5 & 34.4 & & 9.5 & $\mathbf{1 . 1}$ \\
7 Apr 2008 & & 61.4 & 70.15 & 65.6 & & 14.3 & $\mathbf{6 . 8}$ \\
18 Apr 2006 & & 96.15 & 100.5 & 100.13 & & 4.5 & $\mathbf{4 . 1}$ \\
3 Apr 2003 & & 20.1 & 20.4 & 20.3 & & 1.5 & $\mathbf{1}$ \\
21 Apr 2002 & & 65.9 & 42.9 & 41.6 & & $\mathbf{3 4 . 9}$ & 36.9 \\
22 Apr 1995 & & 37.45 & 51.2 & 42.58 & & 36.7 & $\mathbf{1 3 . 7}$ \\
12 May 2010 & 35003 & 12.2 & 14.4 & 13.4 & & 18 & $\mathbf{9 . 8}$ \\
7 Apr 2008 & & 51.9 & 65.16 & 63.4 & & 25.5 & $\mathbf{2 2 . 2}$ \\
18 Apr 2006 & & 85.4 & 93.8 & 93.57 & & 9.8 & $\mathbf{9 . 6}$ \\
3 Apr 2003 & & 3.7 & 3.5 & 3.8 & & 5.4 & $\mathbf{2 . 7}$ \\
21 Apr 2002 & & 24.3 & 28.8 & 26.1 & & 18.5 & $\mathbf{7 . 4}$ \\
22 Apr 1995 & & 113.2 & 127.7 & 127.3 & & 12.8 & $\mathbf{1 2 . 5}$ \\
22 Apr 1995 & 35001 & 83 & 83.3 & 83.3 & & 0.4 & 0.4 \\
\hline
\end{tabular}

It should be noted that the effects of cloud movement on hydrograph modelling become visible only when the study area is divided into sub-basins. In addition, lack of gauges in this study resulted in the use of a flat plane to calculate the
TGCH for the sub-basins; other interpolation methods such as inverse distance weighting and Kriging could be more appropriate to obtain surface data from the point data. Despite this, the similarity between recorded and simulated hydro- 


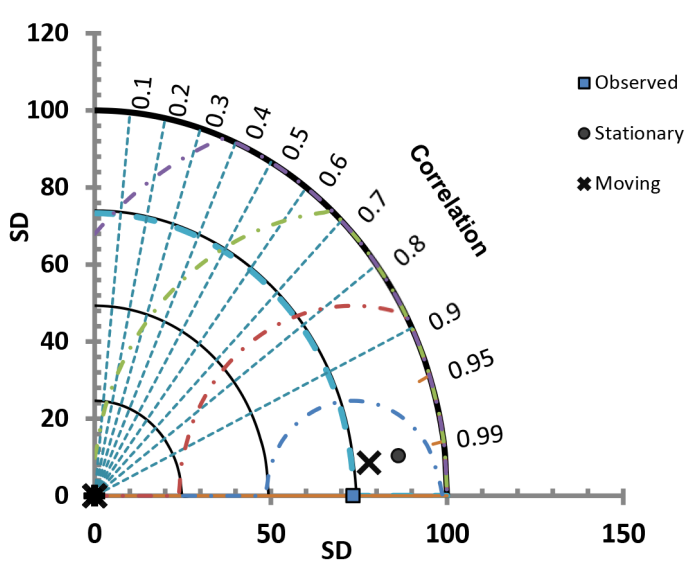

Figure 11. Scatter plot of the simulated peak discharge for stationary and moving conditions on a Taylor diagram.

graph shapes as well as peak discharges indicated that the proposed method could significantly improve runoff modelling accuracy in sparsely gauged large basins.

In conclusion, although there are many laboratory experiments on the effects of rainfall movement on runoff simulation, this study developed an important method to determine how the spatial-temporal dynamics of rainfall can be considered at the real watershed scale, in particular for large areas without sufficient gauges.

\section{Data availability}

The data used in this research were collected from the Ministry of Energy of Iran. The data are provided in the supplement, which can be freely used for research purposes.

\section{The Supplement related to this article is available online at doi:10.5194/hess-20-5063-2016-supplement.}

Acknowledgements. This research was supported by the National Nature Science Foundation of China (no. 91547206, 51425902). The authors are grateful to Catharine Rice for proofreading the manuscript.

Edited by: Y. Chen

Reviewed by: G. Wang and one anonymous referee

\section{References}

Choi, J., Socolofsky, S. A., and Olivera, F.: Hourly disaggregation of daily rainfall in Texas using measured hourly precipitation at other locations, J. Hydrol. Eng., 13, 476-487, 2008.

Costabile, P., Costanzo, C., and Macchione, F.: A storm event watershed model for surface runoff based on $2 \mathrm{D}$ fully dynamic wave equations, Hydrol. Process., 27, 554-569, 2012.

de Lima, J. L. M. P. and Singh, V. P.: The influence of the pattern of moving rainstorms on overland flow, Adv. Water Resour., 25, 817-828, 2002.

de Lima, J. L. M. P., Singh, V. P., and de Lima, M. I. P.: The influence of storm movement on water erosion: storm direction and velocity effects, Catena, 52, 39-56, 2003.

Gyasi-Agyei, Y.: Stochastic disaggregation of daily rainfall into one-hour time scale, J. Hydrol., 309, 178-190, 2005.

Gyasi-Agyei, Y. and Parvez Bin Mahbub, S. M.: A stochastic model for daily rainfall disaggregation into fine time scale for a large region, J. Hydrol., 347, 358-370, 2007.

Howard, A.: Elementary Linear Algebra, 10th Edn., John Wiley \& Sons, Hoboken, NJ, USA, p. 1276, 2010.

Khalighi, S., Mahdavi, M., and Saghafian, B.: Land use change effects on potential flooding, using NRCS model (Case study: Barandoozchay Basin), Iran. J. Nat. Resour., 58, 733-742, 2006.

Khalighi, S., Zinati, T., Salajegheh, A., Kohande, A., and Mortezaee, G.: Estimation of Storm Movement Effect on rainfall-runoff Modeling (Case study: Latian basin), Iran. J. Nat. Resour., 62, 363-375, 2009.

Kim, D. H. and Seo, Y.: Hydrodynamic analysis of storm movement effects on runoff hydrographs and loop-rating curves of a V-shaped watershed, Water Resour. Res., 49, 6613-6623, 2013.

Lee, T., Shin, J., Park, T., and Lee, D.: Basin rotation method for analyzing the directional influence of moving storms on basin response, Stoch. Environ. Res. Risk A., 29, 251-263, 2015.

Maksimov, V. A.: Computing runoff produced by a heavy rainstorm with a moving center, Soviet Hydrol., 5, 510-513, 1964.

Marzen, M., Iserloh, T., de Lima, J. L. M. P., and Johannes, B. R.: Particle transport patterns of short-distance soil erosion by winddriven rain, rain and wind, Geophys. Res. Abstr., 17, 6075-1, 2015.

Mizumura, K. and Ito, Y.: Influence of moving rainstorms on overland flow of an open book type using kinematic wave, J. Hydrol. Eng., 16, 926-934, 2011.

Ngirane, K. G. G. and Wheater, H. S.: Hydrograph sensitivity to storm kinematics, Water Resour. Res., 21, 337-345, 1985.

Ogden, F. L., Richardson, J. R., and Julien, P. Y.: Similarity in catchment response, 2, Moving rainstorms, Water Resour. Res., 31, 1543-1547, 1995.

Saghafian, B., Julien, P. Y., and Ogden, F. L.: Similarity in catchment response, 1, Stationary rainstorms, Water Resour. Res., 31, 1533-1541, 1995.

Sigaroodi, S. K., Chen, Q., Ebrahimi, S., Nazari, A., and Choobin, B.: Long-term precipitation forecast for drought relief using atmospheric circulation factors: a study on the Maharloo Basin in Iran, Hydrol. Earth Syst. Sci., 18, 1995-2006, doi:10.5194/hess18-1995-2014, 2014.

Singh, V. P.: Effect of spatial and temporal variability in rainfall and watershed characteristics on stream flow hydrograph, Hydrol. Process., 11, 1649-1669, 1997. 
Singh, V. P.: Effect of the direction of storm movement on planar flow, Hydrol. Process., 12, 147-170, 1998.

Taylor, K. E.: Summarizing multiple aspects of model performance in a single diagram, J. Geophys. Res., 106, 7183-7192, 2001.

Taylor, K. E.: Taylor Diagram Primer, available at: http://www-pcmdi.llnl.gov/about/staff/Taylor/CV/Taylor_ diagram_primer.pdf (last access: 3 November 2015), 2005.
United States Department of Agriculture: Urban hydrology for small watersheds, (TR-55), 2nd Edn., Natural Resources Conservation Service, conservation engineering division, Washington, D.C., USA, p. 156, 1986.

Yen, B. C. and Chow, V. T.: A laboratory study of surface runoff due to moving rainstorms, Water Resour. Res., 5, 989-1006, 1968. 